\title{
Automated environmental monitoring and database management: Fantasies and realities
}

\author{
by R.A. Benton ${ }^{1}$ and K.M. Pettersen ${ }^{1}$
}

\begin{abstract}
Modern dataloggers and the ever-increasing number of sensors can measure a wide range of environmental parameters, from air temperature and relative humidity through energy flux density, in minute detail and summarize the data for you at any interval your research requires. The cost of collecting environmental data using automated data recorders and their associated sensors continues to drop with advancements in microprocessor development. The value of the data collected by these systems is largely determined by decisions regarding overall project and individual study component design. The utility and versatility of the information collected is a function of the planning performed at the beginning of the research program. The initial design of the monitoring system and the database produced by the system will determine whether or not the data may be useful for other work being conducted on site or nearby. The expected and actual functionality of the database produced can be quite different depending on the resources applied to the monitoring system during initial setup and with ongoing maintenance. This paper incorporates the experiences gained from three long-term research programs involving extensive automated environmental monitoring networks, the problems encountered, the success stories, and the lessons learned. Suggestions and considerations for system design and database management are proposed.
\end{abstract}

Key words: environmental monitoring, system design, database management
Les enregistreurs de donnees modernes et le nombre sans cesse croissant de detecteurs peuvent mesurer une grande variete de parametres environnementaux, allant de la temperature de l'air et de l'humidite relative jusqu'a la densite du flux energetique, et cela dans les moindres details, puis vous resumer les donnees en fonction de n'importe quel intervalle requis par vos recherches. Le cout de collecte des donnees environnementales au moyen d'enregistreurs automatises et des detecteurs qui les accompagnent, continue de diminuer en fonction des progres realises dans le developpement des microprocesseurs. La valeur des donnees recueillies par ces systemes est determinee en grande partie par les decisions se rapportant a l'ensemble du projet et de la conception de chaque composante de l'etude. L'utilite et la versatilite de l'information recueillie sont fonction de la planification apportee des le debut du programme de recherche. La conception initiale du systeme de surveillance ainsi que l'ensemble des donnees produites par le systeme, determinera si les donnees peuvent etre utiles ou non a d'autres travaux entrepris sur le site ou a proximite. L'applicabilite attendue et actuelle de la base de donnees produite peut etre tres differente selon les ressources appliquees au systeme de surveillance au cours de la mise en place initiale et lors de l'entretien courant. Cet expose incorpore l'experience acquise de trois programmes de recherche a long terme comportant des reseaux extensifs de surveillance automatisee de l'environnement, les problemes rencontres, les succes, et les lecons qu'on peut en retirer. Des suggestions et des considerations pour la conception du systeme et la gestion de la base de donnees sont proposees.

Mots-cles: surveillance environnementale, conception de systeme, gestion de base de donnees

\section{Introduction}

Environmental monitoring has many facets, most are realities and some are pure fantasy. The reality is that these data are required to help explain or support the results of experimental treatments. The fantasy is that the environmental data, such as soil temperature or relative humidity, will be easily collected for a minimal cost. This paper suggests a balance that reflects both limitations and possibilities of extended environmental monitoring programs on long-term silvicultural research sites. The information presented here is based on experiences gained from the design and implementation of environmental monitoring and database systems for the Montane Alternative Silvicultural Systems (Arnott et al. 1995), Coastal Forest Chronosequence (Trofymow et al. 1997), and Modifying Silvicultural Systems for Lodgepole Pine (Mitchell 1994) studies.

Environmental data are often incorporated into the design of field experiments where the research site is some distance from another potential source of information, such as airport weather data, or where the type of information required to answer

${ }^{1}$ Natural Resources Canada, Canadian Forest Service, 506 West Burnside Road, Victoria, B.C. V8Z1M5. the questions under study are not collected elsewhere. How far the data that you need can be extrapolated across the landscape and whether the data from another source are relevant to the study site are important considerations in determining what type of data will be collected on site. Therefore, we must first decide whether to collect environmental data and, if we do, we must decide what data, how much, and where. Environmental monitoring system design consideration can assist in guiding this decision-making process.

\section{System Design}

The environmental monitoring system for any project should balance two factors. The first and foremost consideration is acquiring the types of data required to achieve the objectives of the study. The second is cost, of both equipment and installation and available resources for maintenance. While the former is critical for completion of the project, the latter will determine what information can be collected, how useful that information is and whether it may be readily used for the purpose for which it was originally collected. Collecting general climate measurements is also important for comparing long-term records from nearby stations or to account for anomalous events that may affect the results of the experiment as a whole. 
If the environmental monitoring system is a part of a larger project, there are advantages to planning for multiple objectives. This gives greater utility of the data amongst project researchers, a reduction in the duplication of effort, and allows for the addition of low cost supplementary data sets to support studies that start after the initiation of the original project. In the design of such a system, an effort should be made to measure a set of generic or standard environmental elements. These measures include air temperature and relative humidity at 1.3 or $1.4 \mathrm{~m}$, rainfall, and solar radiation. The advantage of collecting these basic measures in conjunction with other more study-specific elements is that these simple measures are good comparators to standard elements measured at airports or other longer-term weather stations. Should a reasonable correlation be developed between the study site measurements and a nearby long-record station, then it is possible to develop site climatologies for specific elements as well as comparisons of inter-annual climate variances that may assist in experimental interpretation. It is preferable to run the monitoring system to collect base data before treatment application. This data will allow for characterization of site differences that can be incorporated in later analyses of the data and will enable testing of the monitoring systems.

Generic measures are important for spatial and temporal comparisons across and between the research sites. However, it will often be necessary to collect very specialized data specific for individual study objectives within the larger project.

Two factors that must be considered in the datalogger system design are sampling rate and integration interval. The sampling rate is how often the sensors are scanned by the datalogger (e.g., every 60 seconds). Factors determining sampling rate are the programming limitations of the datalogger, the response rate of the sensor, the expected rate of change of what is being measured, and power consumption. Depending on the datalogger, it is possible to program increased sampling times during specific events, which reduces power consumption by limiting sensor sampling to important periods. The integration interval is the period of time for which the data summaries are produced (e.g., hourly or daily samples, averages, maxima, or minima). As a matter of practice, it is initially better to integrate the data at a higher resolution as the data can easily be summarized using readily available computer software whereas high-resolution data cannot be generated from low-resolution summaries. An option for accommodating varying integration intervals is to program the datalogger to output higher resolution summaries (hourly, four-hourly, six-hourly) during the growing season or period of most interest for the study and reduce the summary outputs to daily during the remainder of the year. This flexibility allows for a reduced necessity to service stations and helps to avoid data overruns on stations with limited storage memory capacity during periods when the research site is inaccessible. An alternative strategy is to program the datalogger to collect higher resolution summaries for a given period, such as 10 days, each month. This has the advantage of high-resolution summaries over the course of the whole year but the disadvantage of potentially missing significant events in some parts of the year.

Among and within treatment replication for most measured elements is essential. Within treatments, this is particularly true for measurements done in non-homogeneous media such as soils, under-canopy light conditions, under-bark temperatures, or precipitation. Other considerations for sensor replication are spatial variance, sensor drift, and failure. Certain measurements, such as forest soil temperature, require more sensor replication than others, due to the high variation among microsites. Measurements of light or precipitation made under the forest canopy are also highly location-specific due to variations in canopy structure among trees. Replication of such measures serves two purposes. It provides an "average" view of the conditions being measured and it provides backup measurements of the element under study should one of the sensors fail. The need for replication for some elements is not always as critical. For example, there is not a need to replicate solar radiation, precipitation, and air temperature sensors in the center of large clearings, as these elements tend to be spatially similar in areas with no overstory. This does not help if a sensor fails, however, and in this regard, replication provides backup data. The extent of your replication will be determined by both statistical and financial considerations. In general, experience has shown that three replicates in a given setting will provide a reasonable indication of the average conditions being measured.

Next to budget limitations that arise in part from the need to replicate measurements, hardware limitations are the second largest constraint in environmental monitoring. There are commercially available sensors to measure most environmental parameters but there may not be one that can directly measure the specific element you want with the precision required. In addition, the greater the precision and accuracy of the sensor the more it costs, and this will constrain your system design as well.

System power requirements can pose further limitations on system design and will influence what type of sensors you can use, how many sensors and how many replicates of these sensors you can install, and where you can install the system. Many dataloggers will run very efficiently on 12-volt direct current power supplies but the number of sensors will be limited. However, a variety of relatively low-power sensors are available from various manufacturers that can be used to increase measuring capability. In general, there are increased power requirements with an increased sampling rate and number of sensors attached to the recorder system. If the station is to be remotely located, as will most likely be the case for forest research applications, potential power systems are disposable or rechargeable battery packs, generator systems (e.g., diesel, gas, or propane), or solar panel and rechargeable battery systems. All these systems require varying amounts of initial costs and maintenance.

\section{System Maintenance}

All systems require regular servicing and maintenance to check for animal or storm damage, datalogger problems such as lightning damage or moisture buildup, sensor deterioration or failure, and power supply condition. The servicing interval can be defined as the time period for which you can afford to have missing data in your environmental database. During periods of particular interest for a study (e.g., during bud flushing and growth), maintenance should be performed more often (e.g., daily or weekly) than at other times during the year. It is also good practice to service the station more often shortly after installation to check for sensor failure or other initial startup problems. 
A station service log is essential, as this provides a written record to assist in validating data in the aggregate database. The log should contain information about station condition, sensor replacements, repairs, or adjustments, and comments about the current weather conditions. The latter information can be very useful when comparing log entries for changes in sensor function. While on site, a quick scan of the current sensor conditions, as noted in the log, also provides an opportunity to perform instantaneous comparison of replicated sensor response. Anticipate that as sensors age, they will require field or factory recalibration or replacement. The station service $\log$, which contains records of adjusted or replaced sensors, will be an invaluable asset in interpreting anomalous data recovered from the datalogger.

\section{Database Management}

Automated environmental monitoring systems are capable of generating vast amounts of data. Because of this, database creation and management become integral factors in the system design. The data need to be quality controlled for validity of results, adjusted as required, and a database log should be kept. The database component of the project should be considered on both short- and long-term time scales. The shortterm database component consists primarily of data acquired and disseminated during intensive periods of the project. The long-term component consists of archiving the data for potential use after the intensive period of study has ended and by other researchers in the future. While these two components share a great deal, they may be quite different in content.

\section{Quality Control}

Data quality control is a major issue as it ultimately may affect the interpretation of the data and its application for hypothesis testing. When referring to quality control, the main points to consider are whether the data collected falls within reasonable or expected ranges and whether replicated measures are within reasonable agreement. A simple method for validating the collected data is to compare the sensor outputs to manufacturer's range specifications and to standard expected ranges for elements for the day. Expected values for given periods can be acquired from a variety of sources, such as published climatic normals (Environment Canada 1994) or standard meteorological tables (List 1958). Single station weather data can be validated using a variety of methods, such as those described by Meek and Hatfield (1994). Cleaning of the data may require identifying, flagging, or removing individual or sequences of data from the database. Some sensors use the output from other sensors for calibration or adjustment purposes. If the sensor used for adjustment purposes fails then the other sensor data will have to be adjusted or removed from the record. As for station maintenance, a log should be kept at all stages of the database development and archiving. It should consist of detailed notes of specific data adjustments or removal and any generation of new data from the raw data collected from the monitoring stations. It should also include a description of methods used to screen and filter the data. The log should be updated on a regular basis as new data is added to the database.

\section{Data Format}

The format of the data for both short- and long-term archiving is also an important consideration. Ideally, the data should be universally accessible and be readily usable for anyone regardless of what computer or software system they use. The database should be planned for integration with other databases collected in a multi-study project using logical links such as date and time. It should be well documented, not just with data field identifiers and units, but with descriptions of the data collection system as well as sampling and integration schemes. The data should be stored at the accuracy level the sensors are capable of supporting (Spittlehouse 1989). For example, most temperature probes are accurate to $0.1^{\circ} \mathrm{C}$ while the datalogger may measure and store a value with digits at $0.001^{\circ} \mathrm{C}$. Storing the data to $0.01^{\circ} \mathrm{C}$ or higher resolution, particularly for long-term archival purposes, provides a false sense of resolution with which to interpret the data. The format of the database is largely a matter of the personal choice of the database system administrator. Some things to consider in this regard are who is using the data, what is the most useful format for them, are they using highly specialized software that requires a specific format, and is there a format that is generic enough that all users can utilize the data readily. The database should be updated regularly with the most recent data as soon as that data has been screened for quality and validated.

\section{Database Access and Archiving}

For large scale projects involving researchers from a number of organizations, it is important to establish a means of accessing the environmental data easily. One suggested method that has worked successfully is to establish an ftp (file transfer protocol) database server accessible through the Internet. The system can be secure with access limited through a useror project-specific user name and password system and limited access to certain file areas. Ideally, the database site should be accessible throughout the duration of the study and for a reasonable period following the project's termination. For large databases, consideration should be given to supporting a designated contact person who will generate both regular and special request subsets of the data.

Distribution of the interim data summaries and the larger database as a whole is another potential issue. The data should be formatted to be readable on many potential platforms. Data access via the Internet, ftp, or some other method works well for most applications. For larger databases, alternative methods may be required. Such an alternative may be distribution via recordable CDROM using recognized ISO9660 standard format, which can be read by most computer systems. Computer data storage technologies are rapidly advancing and the problem of distribution of large data files may not persist.

Long-term data storage and archiving must be built in at the initial planning stages. Methods of data archiving, regular maintenance, and data descriptions (metafiles) of the archives must be part of this plan. Ensuring that the data may be continue to be accessed off the storage media as storage methods, software, and operating systems change is an important part of the regular maintenance of the archive. The archived data should be stored in a safe area to minimize storage media degradation and, preferably, be stored with copies in other locations. Data archive logs, both digital and hardcopy, should be kept with the storage media.

\section{Summary}

Long-term environmental monitoring provides both invaluable climatic study data and support data for other studies with- 
in a large-scale project. Factors which must be considered during the initial planning of the project are monitoring system design, database management, data summary, analysis, and final archiving.

The design of the environmental monitoring system must: 1) be planned to collect data to help test the study hypothesis, 2 ) have sufficient replication of measures to be statistically valid, and 3) allow for sensor cross-calibration and potential sensor failure. A regular servicing and maintenance schedule will help reduce system failures and data loss. Detailed records of system maintenance will aid in interpreting potentially spurious data.

Database management is much like the monitoring system itself. It requires regular maintenance and servicing as well as a record of development, changes, and adjustments. Raw data collected from the monitoring network will require cleaning and filtering before being included in the database. The database will evolve as it grows to meet the requirements of the various researchers. The final archival database should be smaller than the interim form, as it should not necessarily include replicated sensor readings but rather, data summaries. Archival database maintenance is a necessity and should be accounted for early in the project planning.

Environmental monitoring, like any component of a research project, requires careful consideration and planning. With proper planning and expectations from the beginning of the project, many of the pitfalls associated with the fantasies of monitoring systems can be avoided and the reality will be extremely useful information.

\section{References}

Arnott, J.T., W. J. Beese, A.K. Mitchell and J. Peterson (eds.). 1995. Proceedings of Montane Alternative Silviculture Systems (MASS) Workshop, Courtenay, B.C., June 7-8, 1995. Can. For. Serv. and B.C. Min. For., Victoria, B.C., FRDA Rep. 238. 122 pp.

Environment Canada. 1994. Canadian monthly climate data and 1961-1990 normals. CDROM. Environment Canada, Atmospheric Environment Service, Climate Information Branch. Toronto.

List, R.J. 1958. Smithsonian Meteorological Tables. Smithsonian Institution, Washington, D.C. 527 pp.

Meek, D.W. and J.L. Hatfield. 1994. Data quality checking for single station meteorological databases. Agriculture and Forest Meteorology. 69: 85-109.

Mitchell, J.L. 1994. Commercial Thinning of Mature Lodgepole Pine to Reduce Susceptibility to Mountain Pine Beetle. Can. For. Serv. and B.C. Min. For., Victoria, B.C., FRDA Rep. 224. 20 pp.

Spittlehouse, D.L. 1989. Using dataloggers in the field. Can. For. Serv. and B.C. Min. For., Victoria, B.C., FRDA Rep. 086. 49 pp.

Trofymow, J.A., G.L. Porter, B.A. Blackwell, V. Marshall, R. Arskey, and D. Pollard. 1997. Chronosequences selected for research into the effects of converting coastal British Columbia oldgrowth forests to managed forests: An establishment report. Info. Rep. BC-X-374. Can. For. Ser., Pac. For. Centre, Victoria, B.C. 